\title{
Complete genome sequence and analysis of nine Egyptian females with clinical information from different geographic regions in Egypt
}

Mahmoud ElHefnawi ${ }^{1,2,3 \text { co * }}$, Elsayed Hegazy ${ }^{1 \mathrm{co}}$, Asmaa ElFiky $^{4}$, Yeonsu Jeon ${ }^{5,6}$, Sungwon Jeon ${ }^{5,6}$, Jong Bhak ${ }^{5,6,7}$, Fateheya Mohamed Metwally ${ }^{4}$, Sumio Sugano ${ }^{8}$, Terumi Horiuchi ${ }^{9}$, Abe Kazumi ${ }^{8}$, and Asta Blazyte 5,6 co

co These authors contributed equally to the work.

${ }^{1}$ School of Information Technology and Computer Science, Nile University, Giza, 12588, Egypt.

${ }^{2}$ Informatics \& Systems Department, the National Research Centre, Cairo, Egypt.

${ }^{3}$ Biomedical informatics and chemoinformatics group, center of excellence for Advanced Sciences, informatics and Systems Department, National Research Centre, Cairo, Egypt

${ }^{4}$ Environmental and Occupational medicine department, Environmental Research Division, National Research Centre, Cairo, Egypt.

${ }^{5}$ Korean Genomics Center (KOGIC), UNIST, Republic of Korea.

${ }^{6}$ Department of Biomedical Engineering, School of Life Sciences, Ulsan National Institute of Science and Technology (UNIST), Ulsan, Republic of Korea.

${ }^{7}$ Personal Genomics Institute, Genome Research Foundation, Osong, Republic of Korea.

${ }^{8}$ The Institute of Medical Science, University of Tokyo, Japan.

${ }^{9}$ Graduate School of Frontier Sciences, University of Tokyo, Chiba, Japan

*Corresponding author. E-mail: mahef@aucegypt.edu (ElHefnawi M). 


\begin{abstract}
Egyptians are at a crossroad between Africa and Eurasia, providing useful genomic resources for analyzing both genetic and environmental factors for future personalized medicine. Two personal Egyptian whole genomes have been published previously and here nine female whole genome sequences with clinical information have been added to expand the genomic resource of Egyptian personal genomes. Here we report the analysis of whole genomes of nine Egyptian females from different regions using Illumina short-read sequencers. At 30x sequencing coverage, we identified 12 SNPs that were shared in most of the subjects associated with obesity which are concordant with their clinical diagnosis. Also, we found mtDNA mutation A4282G is common in all the samples and this is associated with chronic progressive external ophthalmoplegia (CPEO). Haplogroup and Admixture analyses revealed that most Egyptian samples are close to the other north Mediterranean, Middle Eastern, and European, respectively, possibly reflecting the into-Africa influx of human migration. In conclusion, we present wholegenome sequences of nine Egyptian females with personal clinical information that cover the diverse regions of Egypt. Although limited in sample size, the whole genomes data provides possible geno-phenotype candidate markers that are relevant to the region's diseases.
\end{abstract}

\title{
Keywords
}

Personal genome - Variant analysis 


\section{Introduction}

Next-generation sequencing (NGS) technology is a powerful approach enabling an efficient study of a large scale genetic variants $[1,2,3,4]$. Whole genome sequencing (WGS) by NGS can cover intronic areas that may contain rare and common deleterious mutations, that cannot be captured by whole exome sequencing (WES) that usually facilitates a deeper coverage of coding regions important for protein function analyses [5]. NGS is also adopted to investigate complex diseases such as obesity and its manifestations such as insulin resistance, impaired glucose tolerance, and dyslipidemia. For instance, Nordang et al. [6] applied NGS technology to target exons and exon-intron junctions in the five obesity-linked genes ( $L E P$, LEPR, MC4R, PCSK1 and POMC) for a Norwegian-based cohort composed of patients with morbid obesity and normal weight controls. They found four variants in $M C 4 R$ gene that were classified as pathogenic or likely pathogenic. Before that, Genome-Wide Association Studies (GWAS) have identified several variants associated with obesity and BMI in the FTO gene [7,8]. Environmental factors such as socioeconomic status and lifestyle, can complement the effect of the obesogenic factors $[9,10,11,12]$. However, the response to the environmental factors can also be ethnic-group specific which makes GWAS difficult to interpret. For example, Caucasians with different genetic backgrounds, but living in a similar obesogenic environment are less susceptible to developing obesity $(\sim 32 \%)$ or T2D $(\sim 8 \%)$ when compared to Pima Indians who live in Arizona where obesity and T2D in those populations were $\sim 64 \%$ and $\sim 30 \%$, respectively $[13,14]$. 
As for Egyptians, obesity studies have exceptional relevance as it is one of the nations with the steepest obesity rate in a 33 yearlong study (1980- 2013) [15]. A study published in 2016 reported more than 30 percent of the Egyptian population to be obese with nearly half of all females being obese (46\%) which is nearly two times the magnitude of this issue in Egyptian males (22\%) [16]. The majority (66\%) of Egyptian women is overweight, in fact, Egyptian women of reproductive age in just 10 years showed an average increase in BMI by $2.21 \mathrm{~kg} / \mathrm{m}^{2}$ [17]. A recent PCR-based study came to a conclusion that LEPR Gln223Arg, UCP2 G 866 A and INSR exon 17 polymorphisms are linked to obesity in Egyptians and some of the risk variants are indeed sex biased [18]. In our previous work the two Egyptian male whole genomes designated as (EGP1 and EGP2) from Delta and Said regions, respectively, shared the SNPs Asn985Tyr in RP1 and Thr55Ala in FABP2 which are associated with an increased level of cholesterol and triglycerides, possibly related to obesity [19].

\section{Materials and methods}

\subsection{Study group and ethical approval}

A total of nine Egyptian females were recruited for this study, all aged $41 \pm 14.35$ years. The subjects (EGY) were enrolled by National Research Center's outpatient clinic and approved by the Medical Research Ethics Committee of the National Research Centre -Egypt (MREC, NRC) with approval number (13177) and with 1964 Helsinki Declaration and its later amendments.

Signed informed consents were obtained from the participants in this study. A clinical examination was conducted for each of them; weight (weight), height (Ht) and waist circumference (WC) were measured. Body mass index (BMI) was calculated according to WHO [20]. Blood pressure was measured for each individual. Five ml of whole blood was centrifuged 
at 12,000 rpm for 10 minutes using (Heraeus Labofuge 400R) centrifuge to separate serum and stored at $-80 \mathrm{C}^{0}$ until analysis.

\subsection{Biochemical Analyses}

Total cholesterol, the levels of triglyceride and High-Density lipoprotein cholesterol (HDL-c) were assessed using an enzymatic colorimetric method by the commercial kits supplied by Centronic GmbH (Wartenberg, Germany). Serum low density lipoprotein cholesterol (LDLC) was estimated using Friedwald's formula.

Fasting serum glucose was assessed using commercial kit (Spinreact,Spain), Fasting serum insulin was estimated by human insulin enzyme immunoassay test kit (Immunospec, USA). Insulin resistance was expressed as homeostasis model assessment of insulin resistance (HOMA-IR) higher than 2.5 [21].

\subsection{Sample collection, DNA isolation and whole genome sequencing}

Genomic DNA was extracted from blood with the GeneJET (Whole Blood) genomic DNA purification Kit (Thermo Scientific, USA), according to manufacturer's protocol. DNA Library preparation was carried out according to the manufacturer's instructions for sequencing on HiSeq2000 (Illumina, San Diego, CA, USA). For demultiplexing and conversion to FASTQ format, CASAVA 1.8.2 (Illumina) was used.

\subsection{Bioinformatics analysis}

\subsubsection{Alignment of reads to reference}

The sequences were mapped to the human reference genome (GRCh38 /hg 38) BWAMEM v.0.7.15 with default options [22]. The SAM files were converted to BAM files using 
samtools 0.1.19 [23]. GATK v.3.5.0 [24] was used for variant calling. Specifically, GATK v.3.5.0 UnifiedGenotyper with options -mbq 30 -stand_emit_conf 50 -stand_call_conf 50.

\subsubsection{Annotation and functional analysis of variants}

The variants were annotated using Annovar v.2018Apr16 [25] and SnpEff tool v4.3i [26]. CRAVAT tool v.4 [27] was used for predicting mutation impact. It employs Variant Effect

Scoring Tool (VEST) which classified mutations as pathogenic or benign. Furthermore, ClinVar database was used [28] to predict the pathogenic mutations.

\subsubsection{Identification of mitochondrial DNA haplogroups}

The paired-end reads aligned to hg19 mitochondrial sequence were realigned to rCRS (Revised Cambridge Reference Sequence [29] and then the variants were used to call haplogroups using HaploGrep software [30].

\subsubsection{Admixture analysis}

To visualize the heterogeneity of the Egyptian lineages we employed ADMIXTURE (v1.3.0) program [31]. We used a total of 80 human origin SNP panel (HOSP) [32] contemporary representative genomes from Europe, West Asia, and various parts of Africa (four per population). The panel was merged with the Egyptian samples and pruned using PLINK (v.1.90) [33] with the option '--indep-pairwise 200250.4 '. We explored the composition of the artificial ancestral populations $(K)$ from two to five to provide the glimpse into the increasing Egyptian genomic complexity as $K$ increases (supplementary figure $\mathrm{S} 1$ ), and chose $K=4$ for the final interpretation because it showed a gradual transition of ancestral component 
proportions from European and West Asian populations to North African as predicted by geographic location (supplementary figure S2). Out of the 9 Egyptian samples, sample EGY3 was excluded due to blood relations with another sample (EGY4) in the dataset to avoid bias.

\section{Results}

\subsection{Clinical characteristics of the study group}

The clinical characteristics of each subject are represented in supplementary Table S1. The mean value of BMI was 32.1 \pm 11.28 ; ranged from (18-45.9), where five cases (aged 44-58 years old) were obese with BMI greater than $30 \mathrm{~kg} / \mathrm{m}^{2}$. Four subjects (aged 20-35 years old) were classified as lean with BMI less than $25 \mathrm{~kg} / \mathrm{m}^{2}$. The mean level of total cholesterol among the research subjects was $192.7 \pm 51.5$. Three cases of hyperlipidemia (aged 29-58 years old) were observed; in one of the cases coinciding with hypertension. Regarding HOMA-IR, the mean value was $2.3 \pm 1.59$ and ranged from 0.9 to 5.08. Two out of the nine subjects (age 50 and 56 years old) were diagnosed with diabetes, and one had HOMA-IR 4.5 but without any confirmed diagnosis. Three out of the nine subjects (EGY3 age 35, EGY4 age 20, and EGY5 age 25 years old) weren't clinically diagnosed with any metabolic syndrome.

\subsection{Genome sequencing and candidate gene identification}

The nine Egyptian females represent different geographic regions in Egypt (supplementary Figure S2). The workflow of the sequence pre-processing, variant calling, annotation and analysis is summarized in eight steps (supplementary Figure S3.). We used an Illumina HiSeq 2500 short-read sequencing and generated approximately 3,099,0381,190 reads of 100 bps length that were aligned to the human reference genome GRCh38/hg 38, resulting in the average depth of coverage of 30x. The basic sequence data are summarized in supplementary Table S2 
From our data, we identified genes associated with obesity, T2D, and MS using the CRAVAT v.4 server and listed the ones with significant association (supplementary Table S3). Among them, we identified five candidate genes for obesity in the Egyptians; CRHR1, VCP, NOTCH3, RHBG, and TMEM63A. Variations in these genes were common within the subjects with BMI $>30 \mathrm{~kg} / \mathrm{m}^{2} . C R H R 1$ and TMEM63A were associated with T2D-diagnosed subjects. Also, NUP88, CRHR1, and WISP1 were associated with high cholesterol trait. The gene CRHRl variations were found in both high cholesterol and T2D patients and therefore this gene is the most feasible obesity and obesity-related disease risk factor we can suggest based on these nine Egyptian females studied.

\subsection{Variants analysis}

We used CRAVAT v.4 server to identify the most significant SNPs in genes using ClinVar and variant effect scoring tool (VEST) score, [34] as well as phenotypes reported in the GWAS catalogue [35] which resulted in a total of 12 SNPs related to metabolic issues and obesity shared among the subjects. Some of them are associated with the pathological conditions confirmed in the Egyptian (EGY) subjects (supplementary Table S4). Among them, we found rs3733402, Ser143Asn in $K L K B 1$ that are associated with obesity according to GWAS catalog, and rs351855, Gly388Arg in FGFR4 that are associated with Waist-to-hip ratio adjusted for body mass index [36].

In the prehypertensive and hypertensive subjects (systolic and diastolic 130/90 \&150/100) with high cholesterol, we found Asp131Glu in C1GALT1C1 (rs17261572, T>A), rs10065172, Leu105 in $I R G M$ and rs1805010, Ile75Val in $I L 4 R$ while in the prediabetic with HOMA-IR $>2.5$ and diabetic participants, we found the following variants: rs1804495, 
Leu303Phe in SERPINA7, rs1800450, Gly54Asp in MBL2, rs1566734, Gln276Pro in PTPRJ, and rs61752717, Met694Val in $M E F V$.

\subsection{Mitochondrial DNA analysis}

The mitochondrial DNA (mtDNA) haplogroups were identified using and MitoSuite 1.0.9 and validated using Haplogrep 2.0 tools (Table 1) and showed diverse maternal ancestral backgrounds associated with Africa, Middle East, Europe or broadly - Mediterranean. The sample EGY1 and EGY2 revealed haplogroups associated with Mediterranean regions, M1a1b found in the north Mediterranean $[37,38,39,40]$ and $\mathrm{T} 2 \mathrm{f}$ found in the European countries, respectively. The eastern Mediterranean region shares severe incidence of obesity with Egypt [41]showing a possible genetic linkage within these countries regarding metabolic profile. Whereas, EGY3 and EGY4 are related samples sharing haplogroup L2a1 and EGY5 had haplogroup $\mathrm{M}$, in both cases, these haplogroups point to an African origin [42]. The strongest mtDNA ancestral connection to the Middle East was shown by EGY8 haplogroup H5 [43], however, such origin could be attributed to EGY6 (H27e) and EGY7 (U8b1a2b) as well EGY8 $[44,45,46]$. EGY7 haplogroup showed a very specific distribution within Jordan and Italy [47,48,49]; possibility of European or Middle Eastern admixture in this sample seems to be reflected in the ADMIXTURE analysis (supplementary Figure S1).man Haplogroup T1a7 found in the EGY9 is associated with very broad distribution within all of the geographic regions described regarding other EGY samples [50,51,52]. Moreover, mitochondrial genome of diabetic subjects and one of three cases of hyperlipidemia, EGY7, EGY9, and EGY2 contained T16189C mutation (Table 2) associated with insulin resistance and type 2 diabetes mellitus $[53,54,55,56]$. Among the variants that were not related to obesity, we found that A4282G 
(Table 2) associated with chronic progressive external ophthalmoplegia (CPEO) was present in all samples [57].

Table 1: List of Haplogroups and locations where they are common regarding each sample.

\begin{tabular}{|c|c|c|c|}
\hline Sample & Haplogroup & $\begin{array}{l}\text { Locations with high } \\
\text { frequesncy }\end{array}$ & $\begin{array}{l}\text { Lower resolution } \\
\text { haplogroups and locations } \\
\text { with high frequency }\end{array}$ \\
\hline EGY1 & M1a1b2 & North Mediterranean [58] & $\begin{array}{l}\text { M1 - eastern Africa/Ethiopia } \\
\text { M1a1 - Mediterranean } \\
\text { region (east Libya, Greece) }\end{array}$ \\
\hline EGY2 & T2f & Europe, Middle East [59] & $\begin{array}{l}\text { T2 - Mediterranean and } \\
\text { central and western Europe } \\
\text { (high freq. in northern } \\
\text { Italy)[59] }\end{array}$ \\
\hline $\begin{array}{l}\text { EGY3, } \\
\text { EGY4 }\end{array}$ & L2a1d1 & Africans $[60,61]$ & L2a1 - Africans $[60,61]$ \\
\hline EGY5 & M3alb & NA & M - northeast Africa [42] \\
\hline EGY6 & $\mathrm{H} 27 \mathrm{e}$ & NA & $\begin{array}{l}\text { H - Europe, Middle East, } \\
\text { Caucasus region }[44,45,46]\end{array}$ \\
\hline EGY7 & U8b1a2b & NA & $\begin{array}{l}\text { U8b - Italy, Jordan } \\
{[47,48,49]}\end{array}$ \\
\hline
\end{tabular}




\begin{tabular}{|l|l|c|l|}
\hline EGY8 & H5 & $\begin{array}{r}\text { Middle East and Western } \\
\text { Caucasus [43] }\end{array}$ & H5 - Middle East and \\
& & NA & T1 - Caucasus, Middle East, \\
EGY9 & T1a7 & Europe, and North and East \\
& & & Africa [50,51,52] \\
\hline
\end{tabular}

Table 2 List of mitochondrial disease associated variants in each sample

\begin{tabular}{|l|l|}
\hline & Mutations (disease associated) \\
\hline EGY1 & T195C, A4282G ,A8108G), A10398G, G15043A, G16129A), A16183C and T16189C \\
\hline EGY2 & T4216C ,A4282G), A4917G), A10398A) and G15928A \\
\hline EGY3 & T195C; A4282G, A10398G T15784C, G16390A and T16519T \\
\hline EGY4 & T195C , A4282G , A10398G (, T15784C, G16390A and 16519 \\
\hline EGY5 & A4282G , A10398G and G15043A \\
\hline EGY6 & A4282G , A10398A ), T16093C and T16519T \\
\hline EGY7 & $\begin{array}{l}\text { T195C ), G3316A, A4282G, G9055A, A10398A, A11467G, A12308G , G12372A, } \\
\text { G14831A, A16183C and T16189C }\end{array}$ \\
\hline EGY8 & A4282G , A10398A ), C16192T and T16519T \\
\hline EGY9 & T4216C , A4282G , A4917G ; A10398A , G15928A and T16189C \\
\hline
\end{tabular}




\subsection{Admixture analysis}

When $K=4$ is chosen (Fig 1), the major ancestral genomic components in Egyptians are dark green and dark blue. While the dark green varied between $81.10 \%$ and $92.43 \%$ among the Egyptian samples, the dark blue composed from $7.56 \%$ to $18.48 \%$ of the artificial Egyptian ancestry. Similar genomic trend was shown when the Tunisians, Algerians, Saharawi and the Bedouin samples used, which points to a strong uniform North African genomic signature, despite of nomadic lifestyle practiced by some of these populations [62,63] which could have resulted in a high admixture rate. However, the components themselves seem to have originated from two main sources: the dark green from the Southern Europe as well as the Middle East and the dark blue mainly from the West Africa as it was found in the highest proportions in the Gambian, Essan, and Yoruba populations. Besides the European/Middle Eastern and West African components small amount and highly variable (from $0.00 \%$ to $1.05 \%$ ) East-Africanassociated component (soft orange) (supplementary Table S5) was found in highest proportions in EGY9, EGY6 and EGY5 among the Egyptian samples. This component had the strongest association with the Hadza indigenous people, however, in smaller proportions was also found among North-Eastern (Ethiopia) and East-Central (Dinka) African populations potentially reflecting genetic drift across the African continent. Most of the Egyptian samples used, especially, EGY5 and EGY9 are closely resembled with Tunisian ancestral proportions while EGY7, EGY8 and EGY2 exhibited higher proportions of the green (Southern European/West Asian) component which were common among the Bedouin. 


\section{Discussion}

There is a limited amount of studies reporting complete genomes using NGS technology from different ethnic groups in North Africa $[19,64,65,66]$, especially, together with clinical data. We detected the variants of the candidate genes, GCAT, SLC6A13, TESK2, VCP, PCNX, and NUP88 using the CRAVAT v.4 server. Also, we found four already reported variants in CRHRl among the subjects who are suffering from severe obesity and metabolic syndrome. Rankinen et al. [67] demonstrated that CRHRI caused human obesity by single-gene mutations. $[68,69]$. Moreover, the participants suffering from obesity and obesity related diseases, (EGY2, EGY6, EGY7, and EGY9) had a SNP rs3733402, 428G>A (Ser143Asn) in KLKB1. This amino acid change has been associated with a Prekallikrein deficiency [70]. Also, we found Gly388Arg in FGFR4 gene (rs351855, 1162G>A) in the participants EGY1, EGY6, and EGY8, which is associated with Waist-to-hip ratio adjusted for body mass index [36]. Moreover, four SNPs were found in pre-diabetic subject with HOMA-IR >2.5 (EGY6), and two diabetic subjects (EGY7, EGY9). One of these SNPs was in $M E F V, 2080 \mathrm{~A}>\mathrm{G}$, Met694Val, rs61752717 that is associated with Familial Mediterranean fever [71]. It is reported that $M E F V$ gene variations affect mostly populations living in the Mediterranean region, especially North African Jews, Armenians, Turks, and Arabs and were also reported in a sequenced Bedouin genome[72].

The mtDNA analysis in the presented study revealed haplogroup for each subject as well as pathogenic mutations that can be transferred from mother to children. A mtDNA T16189C mutation observed in EGY7, EGY9, and EGY2, is already linked with insulin resistance and 
type 2 diabetes mellitus from the pooled case-manipulate research comparing the linkage of T16189C polymorphism with the threat of most cancers and T2DM progression [73]. Regarding other pathogenic mutations, each subject of the nine samples shared mutation A4282G (Table 2) related to chronic progressive external ophthalmoplegia (CPEO Plus) which is a slowly progressing disease that may begin at any age and progresses for fifteen years and often manifests in older age [74].

Overall, both mtDNA and ADMIXTURE studies suggested a diverse and admixed background of Egyptians sharing genetic signature and metabolic phenotypes with other Mediterranean nations. Although largely debated, into-Africa migration hypothesis [75] [76,77] seems to be supported by our largely diverse mtDNA haplotype collection demonstrated by just nine random samples. Egypt standing at the crossroad of different continents could have served as a gateway that allowed circulating people from Eurasia towards Africa since at least Holoscene [75] and lead to admixtures in east and sub-Saharan Africa that were reported before $[76,77]$ and in this case lead to shared genetic predisposition to complex diseases such as obesity.

Our data can be a useful additional genomics resource for the greater genomic research of the nothern Africa and Middle East regions. The haplotype and admixture results point to the diversity of Egyptians, and to a non-African origin for most of them, pointing to the into Africa influx theory.

\section{Conclusions}

Here, we provide nine additional Egyptian genomic resources in terms of short-read based whole genome data and SNPs linked to metabolism-related phenotypes. These nine genomes are a valuable national resource as it contains matching clinical information for each of 
the nine participants. It can facilitate further larger-scale in depth research yielding more relevant variants and greater statistical power.

\section{Data}

The datasets generated in this study are available in the NCBI Sequence Read Archive repository.

\section{Competing interests}

The authors declare no competing interests.

\section{Authors' contributions}

Idea and designed the experiments: MH. Performed the experiments: AE. Sequencing of the whole genomes: SS, TH, AK. Analyzed the data: EH, YJ, SJ, JB, AB. Wrote the paper: AE, EH, AB, JB. Study design, subject recruitment, and sample preparation: AE, FM. Data interpretation: AE, EH, SJ. Contribution to the final draft: AE, ME, SK, AB, SJ, YJ, JB. All authors read and approved the final manuscript.

\section{Acknowledgements}

We thank the National Research Centre clinic for providing for the samples. We thank the pan Asian population genomics initiative (PAPGI) for support with sequencing. This work was supported by U-K BRAND Research Fund (1.190007.01) of UNIST; Research Project Funded by Ulsan City Research Fund (1.190033.01) of UNIST. 


\section{References}

[1] D.R. Bentley, S. Balasubramanian, H.P. Swerdlow, G.P. Smith, J. Milton, C.G. Brown, K.P. Hall, D.J. Evers, C.L. Barnes, H.R. Bignell, Accurate whole human genome sequencing using reversible terminator chemistry, nature, 2008, pp. 53-59.

[2] D.A. Wheeler, M. Srinivasan, M. Egholm, Y. Shen, L. Chen, A. McGuire, W. He, Y.-J. Chen, V. Makhijani, G.T. Roth, The complete genome of an individual by massively parallel DNA sequencing, nature 452 (2008) 872-876.

[3] M.L. Metzker, Sequencing technologies - the next generation, Nature reviews genetics 11 (2010) 31.

[4] M.K. Azim, C. Yang, Z. Yan, M.I. Choudhary, A. Khan, X. Sun, R. Li, H. Asif, S. Sharif, Y. Zhang, Complete genome sequencing and variant analysis of a Pakistani individual, Journal of human genetics 58 (2013) 622-626.

[5] M.J. Bamshad, S.B. Ng, A.W. Bigham, H.K. Tabor, M.J. Emond, D.A. Nickerson, J. Shendure, Exome sequencing as a tool for Mendelian disease gene discovery, Nature Reviews Genetics 12 (2011) 745.

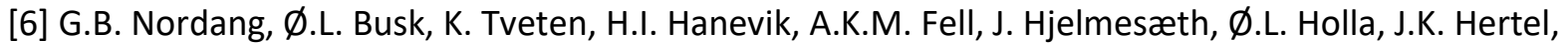
Next-generation sequencing of the monogenic obesity genes LEP, LEPR, MC4R, PCSK1 and POMC in a Norwegian cohort of patients with morbid obesity and normal weight controls, Molecular genetics and metabolism 121 (2017) 51-56.

[7] T.M. Frayling, N.J. Timpson, M.N. Weedon, E. Zeggini, R.M. Freathy, C.M. Lindgren, J.R. Perry, K.S. Elliott, H. Lango, N.W. Rayner, A common variant in the FTO gene is associated with body mass index and predisposes to childhood and adult obesity, Science 316 (2007) 889-894.

[8] R.J. Loos, C.M. Lindgren, S. Li, E. Wheeler, J.H. Zhao, I. Prokopenko, M. Inouye, R.M. Freathy, A.P. Attwood, J.S. Beckmann, Common variants near MC4R are associated with fat mass, weight and risk of obesity, Nature genetics 40 (2008) 768.

[9] R.P. Trevino, R.M. Marshall, D.E. Hale, R. Rodriguez, G. Baker, J. Gomez, Diabetes risk factors in lowincome Mexican-American children, Diabetes care 22 (1999) 202-207.

[10] M. Dehghan, N. Akhtar-Danesh, A.T. Merchant, Childhood obesity, prevalence and prevention, Nutrition journal 4 (2005) 24.

[11] M.G. Harper, Childhood obesity: strategies for prevention, Family \& community health 29 (2006) 288-298.

[12] F.M. Biro, M. Wien, Childhood obesity and adult morbidities-, The American journal of clinical nutrition 91 (2010) 1499S-1505S.

[13] K.S. Vimaleswaran, R.J. Loos, Progress in the genetics of common obesity and type 2 diabetes, Expert reviews in molecular medicine 12 (2010).

[14] H. Choquet, D. Meyre, Genetics of obesity: what have we learned?, Current genomics 12 (2011) 169-179.

[15] M. Ng, T. Fleming, M. Robinson, B. Thomson, N. Graetz, C. Margono, E.C. Mullany, S. Biryukov, C. Abbafati, S.F. Abera, J.P. Abraham, N.M.E. Abu-Rmeileh, T. Achoki, F.S. AlBuhairan, Z.A. Alemu, R. Alfonso, M.K. Ali, R. Ali, N.A. Guzman, W. Ammar, P. Anwari, A. Banerjee, S. Barquera, S. Basu, D.A. Bennett, Z. Bhutta, J. Blore, N. Cabral, I.C. Nonato, J.-C. Chang, R. Chowdhury, K.J. Courville, M.H. Criqui, D.K. Cundiff, K.C. Dabhadkar, L. Dandona, A. Davis, A. Dayama, S.D. Dharmaratne, E.L. Ding, A.M. Durrani, A. Esteghamati, F. Farzadfar, D.F.J. Fay, V.L. Feigin, A. Flaxman, M.H. Forouzanfar, A. Goto, M.A. Green, R. Gupta, N. Hafezi-Nejad, G.J. Hankey, H.C. Harewood, R. Havmoeller, S. Hay, L. Hernandez, A. Husseini, B.T. Idrisov, N. Ikeda, F. Islami, E. Jahangir, S.K. Jassal, S.H. Jee, M. Jeffreys, J.B. Jonas, E.K. Kabagambe, S.E.A.H. Khalifa, A.P. Kengne, Y.S. Khader, Y.-H. Khang, D. Kim, R.W. Kimokoti, J.M. Kinge, Y. Kokubo, S. Kosen, G. Kwan, T. Lai, M. Leinsalu, Y. Li, X. Liang, S. Liu, G. Logroscino, P.A. Lotufo, Y. Lu, J. Ma, N.K. Mainoo, G.A. Mensah, 
T.R. Merriman, A.H. Mokdad, J. Moschandreas, M. Naghavi, A. Naheed, D. Nand, K.M.V. Narayan, E.L. Nelson, M.L. Neuhouser, M.I. Nisar, T. Ohkubo, S.O. Oti, A. Pedroza, et al., Global, regional, and national prevalence of overweight and obesity in children and adults during 19802013: a systematic analysis for the Global Burden of Disease Study 2013, The Lancet 384 (2014) 766-781.

[16] R. Alebshehy, N.M. Shuaib, J.D. Mbako, D. Barffo, R. KuuzagrNuotol, Determinant analysis of obesity among adult females in Egypt, The Egyptian Journal of Hospital Medicine 31 (2016) 1-8.

[17] A.M. Austin, A.G. Hill, W.W. Fawzi, Maternal obesity trends in Egypt 1995-2005, Maternal \& child nutrition 9 (2013) 167-179.

[18] N.E. Hassan, S.A. El-Masry, W. Zarouk, R.A. El Banna, R.M. Mosaad, M. Al-Tohamy, A.R. Salamah, Obesity phenotype in relation to gene polymorphism among samples of Egyptian children and their mothers, Genes \& diseases 5 (2017) 150-157.

[19] M. ElHefnawi, S. Jeon, Y. Bhak, A. ElFiky, A. Horaiz, J. Jun, H. Kim, J. Bhak, Whole genome sequencing and bioinformatics analysis of two Egyptian genomes, Gene 668 (2018) 129-134.

[20] W.H. Organization, Obesity: preventing and managing the global epidemic, World Health Organization, 2000.

[21] T. Reinehr, W. Kiess, T. Kapellen, W. Andler, Insulin sensitivity among obese children and adolescents, according to degree of weight loss, Pediatrics 114 (2004) 1569-1573.

[22] H. Li, R. Durbin, Fast and accurate short read alignment with Burrows-Wheeler transform, Bioinformatics 25 (2009) 1754-1760.

[23] H. Li, B. Handsaker, A. Wysoker, T. Fennell, J. Ruan, N. Homer, G. Marth, G. Abecasis, R. Durbin, The sequence alignment/map format and SAMtools, Bioinformatics 25 (2009) 2078-2079.

[24] A. McKenna, M. Hanna, E. Banks, A. Sivachenko, K. Cibulskis, A. Kernytsky, K. Garimella, D. Altshuler, S. Gabriel, M. Daly, The Genome Analysis Toolkit: a MapReduce framework for analyzing nextgeneration DNA sequencing data, Genome research 20 (2010) 1297-1303.

[25] K. Wang, M. Li, H. Hakonarson, ANNOVAR: functional annotation of genetic variants from highthroughput sequencing data, Nucleic acids research 38 (2010) e164-e164.

[26] P. Cingolani, A. Platts, L.L. Wang, M. Coon, T. Nguyen, L. Wang, S.J. Land, X. Lu, D.M. Ruden, A program for annotating and predicting the effects of single nucleotide polymorphisms, SnpEff: SNPs in the genome of Drosophila melanogaster strain w1118; iso-2; iso-3, Fly 6 (2012) 80-92.

[27] C. Douville, H. Carter, R. Kim, N. Niknafs, M. Diekhans, P.D. Stenson, D.N. Cooper, M. Ryan, R. Karchin, CRAVAT: cancer-related analysis of variants toolkit, Bioinformatics 29 (2013) 647-648.

[28] M.J. Landrum, J.M. Lee, M. Benson, G. Brown, C. Chao, S. Chitipiralla, B. Gu, J. Hart, D. Hoffman, J. Hoover, ClinVar: public archive of interpretations of clinically relevant variants, Nucleic acids research 44 (2015) D862-D868.

[29] R.M. Andrews, I. Kubacka, P.F. Chinnery, R.N. Lightowlers, D.M. Turnbull, N. Howell, Reanalysis and revision of the Cambridge reference sequence for human mitochondrial DNA, Nat Genet 23 (1999) 147.

[30] A. Kloss-Brandstätter, D. Pacher, S. Schönherr, H. Weissensteiner, R. Binna, G. Specht, F. Kronenberg, HaploGrep: a fast and reliable algorithm for automatic classification of mitochondrial DNA haplogroups, Human mutation 32 (2011) 25-32.

[31] D.H. Alexander, J. Novembre, K. Lange, Fast model-based estimation of ancestry in unrelated individuals, Genome research 19 (2009) 1655-1664.

[32] I. Lazaridis, N. Patterson, A. Mittnik, G. Renaud, S. Mallick, K. Kirsanow, P.H. Sudmant, J.G. Schraiber, S. Castellano, M. Lipson, Ancient human genomes suggest three ancestral populations for present-day Europeans, Nature 513 (2014) 409. 
[33] S. Purcell, B. Neale, K. Todd-Brown, L. Thomas, M.A. Ferreira, D. Bender, J. Maller, P. Sklar, P.I. De Bakker, M.J. Daly, PLINK: a tool set for whole-genome association and population-based linkage analyses, The American journal of human genetics 81 (2007) 559-575.

[34] H. Carter, C. Douville, P.D. Stenson, D.N. Cooper, R. Karchin, Identifying Mendelian disease genes with the variant effect scoring tool, BMC genomics 14 (2013) S3.

[35] J. MacArthur, E. Bowler, M. Cerezo, L. Gil, P. Hall, E. Hastings, H. Junkins, A. McMahon, A. Milano, J. Morales, The new NHGRI-EBI Catalog of published genome-wide association studies (GWAS Catalog), Nucleic acids research 45 (2016) D896-D901.

[36] M. Rask-Andersen, T. Karlsson, W.E. Ek, Å. Johansson, Genome-wide association study of body fat distribution identifies adiposity loci and sex-specific genetic effects, Nature communications 10 (2019) 339-339.

[37] A. Stevanovitch, A. Gilles, E. Bouzaid, R. Kefi, F. Paris, R. Gayraud, J. Spadoni, F. El-Chenawi, E. Béraud-Colomb, Mitochondrial DNA sequence diversity in a sedentary population from Egypt, Annals of human genetics 68 (2004) 23-39.

[38] J.L. Saunier, J.A. Irwin, K.M. Strouss, H. Ragab, K.A. Sturk, T.J. Parsons, Mitochondrial control region sequences from an Egyptian population sample, Forensic Science International: Genetics 3 (2009) e97-e103.

[39] C. Winters, The African origin of mtDNA haplogroup M1, Europe 17 (2010) 14.15.

[40] A.M. González, J.M. Larruga, K.K. Abu-Amero, Y. Shi, J. Pestano, V.M. Cabrera, Mitochondrial lineage M1 traces an early human backflow to Africa, BMC genomics 8 (2007) 223.

[41] A.O. Musaiger, Overweight and obesity in the Eastern Mediterranean Region: can we control it?, (2004).

[42] L. Quintana-Murci, O. Semino, H.-J. Bandelt, G. Passarino, K. McElreavey, A.S. SantachiaraBenerecetti, Genetic evidence of an early exit of Homo sapiens sapiens from Africa through eastern Africa, Nature genetics 23 (1999) 437.

[43] H. Ennafaa, V.M. Cabrera, K.K. Abu-Amero, A.M. González, M.B. Amor, R. Bouhaha, N. Dzimiri, A.B. Elgaaïed, J.M. Larruga, Mitochondrial DNA haplogroup H structure in North Africa, BMC genetics 10 (2009) 8.

[44] A. Achilli, C. Rengo, C. Magri, V. Battaglia, A. Olivieri, R. Scozzari, F. Cruciani, M. Zeviani, E. Briem, V. Carelli, The molecular dissection of mtDNA haplogroup $\mathrm{H}$ confirms that the Franco-Cantabrian glacial refuge was a major source for the European gene pool, The American Journal of Human Genetics 75 (2004) 910-918.

[45] P. Brotherton, W. Haak, J. Templeton, G. Brandt, J. Soubrier, C.J. Adler, S.M. Richards, C. Der Sarkissian, R. Ganslmeier, S. Friederich, Neolithic mitochondrial haplogroup H genomes and the genetic origins of Europeans, Nature communications 4 (2013) 1764.

[46] U. Roostalu, I. Kutuev, E. Loogväli, E. Metspalu, K. Tambets, M. Reidla, E. Khusnutdinova, E. Usanga, T. Kivisild, R. Villems, Origin and expansion of haplogroup $H$, the dominant human mitochondrial DNA lineage in West Eurasia: the Near Eastern and Caucasian perspective, Molecular biology and evolution 24 (2006) 436-448.

[47] C. Turchi, L. Buscemi, C. Previderè, P. Grignani, A. Brandstätter, A. Achilli, W. Parson, A. Tagliabracci, Italian mitochondrial DNA database: results of a collaborative exercise and proficiency testing, International journal of legal medicine 122 (2008) 199-204.

[48] P. Grignani, C. Turchi, A. Achilli, G. Peloso, M. Alù, U. Ricci, C. Robino, S. Pelotti, E. Carnevali, I. Boschi, Multiplex mtDNA coding region SNP assays for molecular dissection of haplogroups $\mathrm{U} / \mathrm{K}$ and J/T, Forensic Science International: Genetics 4 (2009) 21-25.

[49] A.M. González, O. García, J.M. Larruga, V.M. Cabrera, The mitochondrial lineage U8a reveals a Paleolithic settlement in the Basque country, BMC genomics 7 (2006) 124. 
[50] E. Metspalu, T. Kivisild, K. Kaldma, J. Parik, M. Reidla, K. Tambets, R. Villems, The Trans-Caucasus and the expansion of the Caucasoid-specific human mitochondrial DNA, Genomic Diversity, Springer, 1999, pp. 121-133.

[51] S. Bonfiglio, C. Ginja, A. De Gaetano, A. Achilli, A. Olivieri, L. Colli, K. Tesfaye, S.H. Agha, L.T. Gama, F. Cattonaro, Origin and spread of Bos taurus: new clues from mitochondrial genomes belonging to haplogroup T1, PloS one 7 (2012) e38601.

[52] D. Rowold, J. Luis, M. Terreros, R.J. Herrera, Mitochondrial DNA geneflow indicates preferred usage of the Levant Corridor over the Horn of Africa passageway, Journal of human genetics 52 (2007) 436.

[53] J. Poulton, M.S. Brown, A. Cooper, D. Marchington, D. Phillips, A common mitochondrial DNA variant is associated with insulin resistance in adult life, Diabetologia 41 (1998) 54-58.

[54] J. Poulton, A. Bednarz, M. Scott-Brown, C. Thompson, V. Macaulay, D. Simmons, The presence of a common mitochondrial DNA variant is associated with fasting insulin levels in Europeans in Auckland, Diabetic medicine 19 (2002) 969-971.

[55] K.S. Park, J. Chan, L.-M. Chuang, S. Suzuki, E. Araki, K. Nanjo, L. Ji, M. Ng, M. Nishi, H. Furuta, A mitochondrial DNA variant at position 16189 is associated with type 2 diabetes mellitus in Asians, Diabetologia 51 (2008) 602-608.

[56] J.-H. Kim, K.S. Park, Y.M. Cho, B. Kang, S. Kim, H. Jeon, S. Kim, H. Lee, The prevalence of the mitochondrial DNA 16189 variant in non-diabetic Korean adults and its association with higher fasting glucose and body mass index, Diabetic medicine 19 (2002) 681-684.

[57] C.B. Jackson, C. Neuwirth, D. Hahn, J.-M. Nuoffer, S. Frank, S. Gallati, A. Schaller, Novel mitochondrial tRNAlle m. 4282A $>\mathrm{G}$ gene mutation leads to chronic progressive external ophthalmoplegia plus phenotype, British journal of ophthalmology 98 (2014) 1453-1459.

[58] E. Pennarun, T. Kivisild, E. Metspalu, M. Metspalu, T. Reisberg, J.-P. Moisan, D.M. Behar, S.C. Jones, R. Villems, Divorcing the Late Upper Palaeolithic demographic histories of mtDNA haplogroups M1 and U6 in Africa, BMC Evolutionary Biology 12 (2012) 234.

[59] M. Pala, A. Olivieri, A. Achilli, M. Accetturo, E. Metspalu, M. Reidla, E. Tamm, M. Karmin, T. Reisberg, B.H. Kashani, Mitochondrial DNA signals of late glacial recolonization of Europe from near eastern refugia, The American journal of human genetics 90 (2012) 915-924.

[60] M.W. Allard, D. Polanskey, K. Miller, M.R. Wilson, K.L. Monson, B. Budowle, Characterization of human control region sequences of the African American SWGDAM forensic mtDNA data set, Forensic science international 148 (2005) 169-179.

[61] D.C. Johnson, S. Shrestha, H.W. Wiener, R. Makowsky, A. Kurundkar, C.M. Wilson, B. Aissani, Mitochondrial DNA diversity in the African American population, Mitochondrial DNA 26 (2015) 445-451.

[62] E. Losleben, The Bedouin of the Middle East, Lerner Publications, 2003.

[63] C. Catassi, I.-M. Ratsch, L. Gandolfi, R. Pratesi, E. Fabiani, R. El Asmar, M. Frijia, I. Bearzi, L. Vizzoni, Why is coeliac disease endemic in the people of the Sahara?, The Lancet 354 (1999) 647-648.

[64] M. Ilyas, J.-S. Kim, J. Cooper, Y.-A. Shin, H.-M. Kim, Y.S. Cho, S. Hwang, H. Kim, J. Moon, O. Chung, Whole genome sequencing of an ethnic Pathan (Pakhtun) from the north-west of Pakistan, BMC genomics 16 (2015) 172.

[65] M.K. Azim, C. Yang, Z. Yan, M.I. Choudhary, A. Khan, X. Sun, R. Li, H. Asif, S. Sharif, Y. Zhang, Complete genome sequencing and variant analysis of a Pakistani individual, Journal of human genetics 58 (2013) 622.

[66] G. Thareja, S.E. John, P. Hebbar, K. Behbehani, T.A. Thanaraj, O. Alsmadi, Sequence and analysis of a whole genome from Kuwaiti population subgroup of Persian ancestry, BMC genomics 16 (2015) 92. 
[67] T. Rankinen, A. Zuberi, Y.C. Chagnon, S.J. Weisnagel, G. Argyropoulos, B. Walts, L. Pérusse, C. Bouchard, The human obesity gene map: the 2005 update, Obesity 14 (2006) 529-644.

[68] J. Licinio, F. O'kirwan, K. Irizarry, B. Merriman, S. Thakur, R. Jepson, S. Lake, K. Tantisira, S. Weiss, M. Wong, Association of a corticotropin-releasing hormone receptor 1 haplotype and antidepressant treatment response in Mexican-Americans, Molecular psychiatry 9 (2004) 1075.

[69] Z. Liu, F. Zhu, G. Wang, Z. Xiao, J. Tang, W. Liu, H. Wang, H. Liu, X. Wang, Y. Wu, Association study of corticotropin-releasing hormone receptor 1 gene polymorphisms and antidepressant response in major depressive disorders, Neuroscience letters 414 (2007) 155-158.

[70] I. Katsuda, F. Maruyama, K. Ezaki, T. Sawamura, Y. Ichihara, A new type of plasma prekallikrein deficiency associated with homozygosity for Gly104Arg and Asn124Ser in apple domain 2 of the heavy-chain region, Eur J Haematol 79 (2007) 59-68.

[71] M. Shohat, G.J. Halpern, Familial Mediterranean fever--a review, Genet Med 13 (2011) 487-498.

[72] L. Mohammadnejad, S. Farajnia, Mediterranean Fever gene analysis in the azeri turk population with familial mediterranean Fever: evidence for new mutations associated with disease, Cell journal 15 (2013) 152-159.

[73] T. Kumari, M. Vachher, S. Bansal, R.N. Bamezai, B. Kumar, Meta-analysis of mitochondrial T16189C polymorphism for cancer and Type 2 diabetes risk, Clinica Chimica Acta 482 (2018) 136-143.

[74] Z.-Y. Lv, X.-M. Xu, X.-F. Cao, Q. Wang, D.-F. Sun, W.-J. Tian, Y. Yang, Y.-Z. Wang, Y.-L. Hao, Mitochondrial mutations in $12 \mathrm{~S}$ rRNA and $16 \mathrm{~S}$ rRNA presenting as chronic progressive external ophthalmoplegia (CPEO) plus: A case report, Medicine 96 (2017).

[75] M. Haber, M. Mezzavilla, A. Bergström, J. Prado-Martinez, P. Hallast, R. Saif-Ali, M. Al-Habori, G. Dedoussis, E. Zeggini, J. Blue-Smith, Chad genetic diversity reveals an African history marked by multiple Holocene Eurasian migrations, The American Journal of Human Genetics 99 (2016) 1316-1324.

[76] G.B. Busby, G. Band, Q.S. Le, M. Jallow, E. Bougama, V.D. Mangano, L.N. Amenga-Etego, A. Enimil, T. Apinjoh, C.M. Ndila, Admixture into and within sub-Saharan Africa, Elife 5 (2016) e15266.

[77] M.G. Llorente, E.R. Jones, A. Eriksson, V. Siska, K. Arthur, J. Arthur, M. Curtis, J.T. Stock, M. Coltorti, P. Pieruccini, Ancient Ethiopian genome reveals extensive Eurasian admixture in Eastern Africa, Science 350 (2015) 820-822. 
bioRxiv preprint doi: https://doi.org/10.1101/2020.03.10.985317; this version posted March 11, 2020. The copyright holder for this preprint (which was not certified by peer review) is the author/funder. All rights reserved. No reuse allowed without permission.

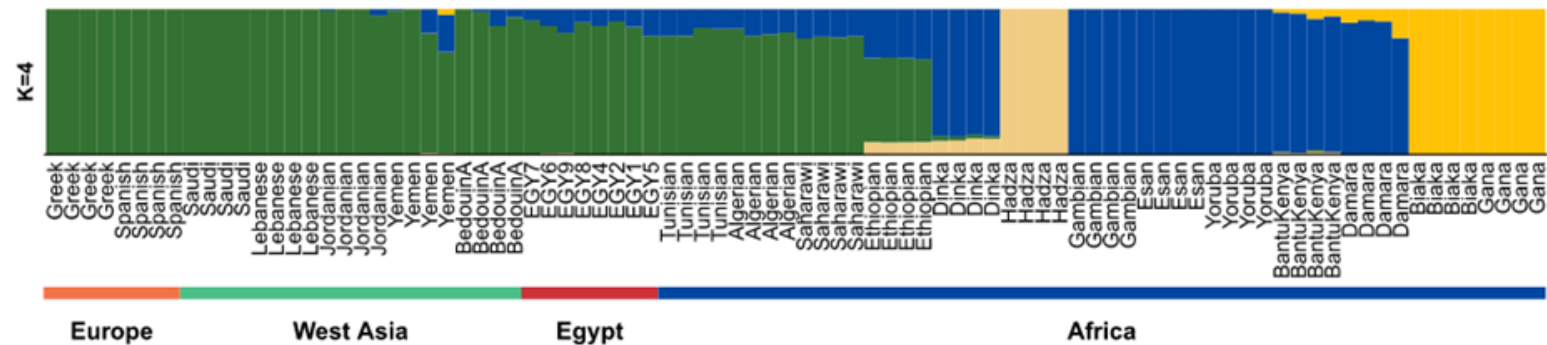

Figure 1: The ancestral composition of Egyptians in comparison to other populations when $\mathrm{K}=4$ 